\title{
Broad Motives in Short Scales -
}

\section{A Questionnaire for the Zurich Model of Social Motivation}

\author{
Felix D. Schönbrodt \\ Department of Psychology \\ Humboldt University Berlin, Germany \\ Sven R. Unkelbach \\ Department of Psychology \\ Saarland University, Germany \\ Frank M. Spinath \\ Department of Psychology \\ Saarland University, Germany
}

Correspondence address:

Felix Schönbrodt, Oberländer Str. 63a, D-86163 Augsburg, Germany.

Email: felix.schoenbrodt@web.de 
Abstract: We introduce a new questionnaire which measures interindividual differences in five motivational systems (Security, Arousal, Power, Prestige and Achievement) with six items per scale. As a theoretical base of our work we referred to the Zurich Model of Social Motivation, which describes and models these motivational systems in a system theoretic way. The questionnaire is formulated in German and called "Motive Profile following the Zurich Model (MPZM)". Data indicate that the questionnaire shows good psychometric properties with Cronbach's $\alpha>0.73$ and an excellent factorial structure $(n=1243)$. To assess convergent and discriminant validity, the MPZM was compared with the Personality Research Form (PRF-D), the Multi-Motive-Grid (MMG) and the NEO-FFI in a multitrait-multimethodanalysis and a scale level factor analysis $(n=190)$. The MPZM showed convergent validity to content matched scales of the PRF ( $\mathrm{r}=0.55$ ), no differentiated relationship to the MMG and few correlations to the NEO-FFI. First indications of external validity were studied through biographical data. MPZM was able to predict them with adjusted multiple Rs of up to $\mathrm{r}=0.40$ and outperformed both NEO-FFI and MMG in predictive power and incremental validity. Keywords: motivation, evolution, Zurich Model of Social Motivation, questionnaire construction and validation.

\section{Introduction}

What are the basic social motivations of humans? In this study we rely on a model of human motivation that is grounded on an evolutionary basis, providing a variety of ethological, cultural anthropological and psychological support: the Zurich Model of Social Motivation (in short: ZM) developed by Bischof $(1975 ; 1993 ; 2001)$. The model postulates that three basic motivational systems have developed in human phylogeny: (a) the security system, (b) the arousal system and (c) the autonomy system. The autonomy system is furthermore divided 
into three phylogenetically distinguishable motives: power, prestige and achievement. Antecessors or equivalents of these three basic motivational systems can be found in virtually all mammals. In the ZM, all these motivational systems are formalized in a system theoretic model, which specifies the interactions between these components.

Despite the clear appreciation of the theoretical status of the model (Lamb \& Keller, 1991; Block, 2002; Lamb, Bornstein, \& Teti, 2002; Asendorpf, 2004; Pollak, 2005), to this day no applicable measure for interindividual differences in the parameters of the ZM has been developed (the procedure applied by Gubler and Bischof, 1993, is methodologically sophisticated but not applicable for a broad usage).

\section{The Zurich Model of Social Motivation}

The ZM is a formalized theory of social motivation, developed from an evolutionary, ethological and developmental point of view. As mentioned above, it proposes three basic motivational subsystems which interact in a highly interconnected way. These systems are modeled in a system theoretic approach, hence simulations can be computed and compared with empirical data (Bischof, 1975; 1993). All subsystems are formalized as feedback control systems, which compare an actual value with a set point and strive to reduce emerging differences to maintain a homeostatic condition. The actual value can both exceed and fall below the set point, and in both cases a specific behavioral reaction is triggered to regulate this unbalance (Gubler \& Bischof, 1991). As the theory is quite complex in the interactions of the motivational systems, we have to refer to the original literature. In the following sections, only the main components are shortly described, as far as necessary for the understanding of the MPZM scales.

\section{The Security System}

The security system deals with the regulation of the distance to familiar social objects and is a formalization and expansion of Bowlby's "attachment system" (Bowlby, 1980). In early 
childhood, the security system controls the distance to the primary care-giver (usually the mother) and ensures that for surviving purposes the contact is not lost. The actual value of (subjective) security rises if a familiar, relevant and nearby conspecific is present (Gubler \& Bischof, 1991).

The set point for the security system is labeled "dependency" and depicts a hypothetical intraorganismic variable that describes the need of being reassured. Whenever the actual level of felt security falls short of the dependency, attachment behavior is triggered with the aim to reduce the distance to the partner or the care-giver. But the security level can also overstep the dependency - and at this point the ZM exceeds the conception of Bowlby, who only dealt with a lack of security. An overabundance of security is best illustrated in puberty: In this case surfeit behavior is triggered, with the aim to reduce the level of security. In adulthood, the security system still keeps working and deals with the regulation of close, romantic relationships (pair bonding or secondary attachment; Hazan \& Shaver, 1994).

\section{The Arousal System}

A large amount of survival problems deals with behavior towards unknown objects or objects that are hard to assess, for example strangers, predators or environmental hazards. In this case a second homeostatic motivational system controls behavior: the arousal system. It responds to unfamiliar, relevant and nearby objects. The more each of these criteria is fulfilled, the higher is the subjective actual level of arousal.

The internal set point for this system is labeled "enterprise". Whenever the felt arousal oversteps this internal level, fear is the emotional reaction with a prototypical behavioral reaction of withdrawing. But - as in the security system - the actual level of arousal can also fall below the set point. In this case, the organism is in a motivational state of appetence towards arousal and will show exploratory behavior. 
The autonomy system regulates social behavior in respect to rank-order and dominance. The actual value of perceived success is constantly compared with the internal set point of autonomy claim. The perceived success falls short of the claim, when for example a low ranking individual challenges the position of a higher ranked. This leads to assertive behavior, which has the aim to reestablish the hierarchical position. If the own success exceeds the claim, submissive behavior is triggered to re-match the actual value to the set point. These two reactions - assertive and submissive behavior - correspond to the phylogenetic oldest part of the autonomy system, the power motive (also see below). Hence these reactions should rather be seen as prototypic than as exhaustive reactions of the autonomy system. Bischof distinguishes three components of the autonomy system. The first component, the power motive, is the phylogenetic oldest part and can be found in many mammals living in groups. It is basically dealing with hierarchy and dominance issues. In contrast to this dominance hierarchy, the second component - the prestige motive - deals with a prestige hierarchy. In this hierarchy the one receiving the most attention from others is the one with the highest rank. The prestige hierarchy is first found on the hominid level as it requires specific cognitive adaptations (Bischof, 1993). The third component of the autonomy system is the achievement motive. This is a specific human motivation, and though it seems to be quite distinct from the basal autonomy claim in dominance hierarchies, both share the feeling of competence, autonomy and self efficacy and belong therefore to the autonomy system.

One important distinction has to be made concerning attachment/bonding and sexuality: whereas attachment (both to the parents and to the adult partner) is assigned to the security system, sexuality is in the ZM strongly connected to the autonomy system. Therefore both functions (and subjective feelings) should not be mixed up in a superordinate concept like "love" (Bischof, 1993; see also Diamond, 2004). 
According to the ZM, all of these motivational systems are functionally interconnected. The most basic interconnections are between the three components of the autonomy system. Furthermore, the autonomy system should be functionally in a positive connection to the arousal system and in a negative connection to the security system. That means, a high autonomy facilitates exploratory behavior and suppresses dependency.

\section{Objective}

Up to now there is no specific instrument to measure the parameters of the model which is easy to administer. Although there are several instruments for single motives, e.g. the Dominance scale in the PRF (Jackson, 1967), they differ either in abstraction or in the specific conception. Therefore, the aim of this study was the construction and validation of a questionnaire based on the ZM, which reliably measures interindividual differences in the set points of the five motivational subsystems "Security", "Arousal", "Power", "Prestige" and "Achievement" in adults. The inventory is designed as an explicit measure of motives (for the distinction of explicit vs. implicit motives see for example McClelland, Koestner, \& Weinberger, 1989; Schultheiss, 2001) and should cover a broad range of human motivation with short, economic scales.

\section{Study I: Inventory Construction}

\section{Materials and Methods}

\section{Participants}

The sample of participants in this study included 1243 (66\% female) German-speaking individuals who voluntarily completed the questionnaire at an online study. The average age was 29 years ( $\mathrm{SD}=9.6$; range $18-64$ years), $23 \%$ of the sample reported to be students. 


\section{Item-Pool and Selection}

An item-pool of 15-17 German items per dimension was constructed $(n=78)$. All items were formulated as statements and designed to capture the scale in a broad sense (sample items Security: "I feel uncomfortable if no familiar people are with me./ Affiliations are very important to me."; Arousal: "I love thrill./ In my leisure time I seek situations that may be a bit dangerous.”; Power: "I like taking over leadership in a team./ Sometimes I carry my point against other's wishes."; Prestige: "It is important to me that my partner speaks very well of me./ A success without praise is less worthy for me."; Achievement: "It is important for me to show good achievements./ In my occupation I do much more than is expected from me"). The author of the ZM cross-checked and approved these items for content validity. Participants responded on a 5-point Likert-scale, indicating the degree to which this item adequately describes their behavior (very untypical ... very typical).

For item selection, the sample was divided into two random equal-sized subsamples (optimization sample and validation sample). All analyses and selection steps were only applied to the optimization sample, the validation sample was used for cross-validation. In the item selection procedure both internal consistencies as well as the factorial structure were optimized. After item selection, the final Cronbach's $\alpha$ for each scale was computed. Scales were computed as the unweighted average of item scores. To assess the dimensionality of the questionnaire, an exploratory principle axis factor analysis was conducted. As the scales are theoretically not assumed to be independent, afterwards a Promax factor rotation $(\mathrm{kappa}=4)$ was applied.

Concerning intercorrelations of scales, we expected moderate correlations between the components of the autonomy system (i.e. power, prestige and achievement). As the connection between autonomy, security and arousal (described above) is a functional one (i.e. 
a rise in autonomy claim leads to a intraindividual rise in enterprise), we had no specific expectations about these intercorrelations at group level.

\section{Results}

After item selection, six items were kept per scale, yielding a total of 30 items. Cronbach's $\alpha$ ranged from 0.73 to 0.82 in the optimization sample and from 0.71 to 0.80 in the validation sample (see Table 1).

\section{--- TABLE 1 ABOUT HERE ---}

A Kaiser-Meyer-Olkin MSA of 0.86 and Bartlett's test of sphericity $(\mathrm{p}<0.000)$ suggested that the data of the optimization sample were suitable for factor analysis. A principal axis factor analysis revealed six eigenvalues $>1$ in the original, unrotated solution: 5.60, 4.10, 2.40, 1.78, 1.33 and 1.07. However, a parallel analysis (Horn, 1965) clearly indicated a five factor solution accounting for $51 \%$ of the variance. The pattern matrix from a five-factor principal axis extraction with Promax rotation revealed a simple structure with all items loading highest on the correct factor and no secondary loading exceeding 0.30 . It was possible to replicate these findings in the validation sample, where 29 out of 30 items (97\%) scored highest on the correct factor. Only one item had a higher loading on an improper factor and the second highest loading on the correct factor. However, in an analysis of the complete sample all items scored highest on the proper factor, therefore all items were kept in the inventory for study II.

\section{Study II: Inventory Validation}

\section{Material and Methods}

\section{Participants}

The complete sample for the validation study included 190 participants (72 male, 116 female) 
with an average age of 27 years ( $\mathrm{SD}=11.0$; range $17-63$ years). Approximately $47 \%$ of the sample were students with different majors. There was no overlap to the construction sample.

\section{Questionnaires}

For construct validation, participants completed the MPZM (in the reduced 30-item version from study I) along with three additional personality questionnaires. As another explicit motive-based questionnaire we chose the German adaptation of the Personality Research Form (PRF-D; Jackson, 1967; Stumpf et al., 1985). With 14 scales and a total of 234 items, this questionnaire covers a broad range of human motivation based on Murray‘s (1938) needs theory and clearly addresses a more specific level than the MPZM.

Additionally the participants completed the Multi-Motiv-Gitter (MMG; Schmalt, Sokolowski, \& Langens, 2000; Sokolowski, Schmalt, Langens, \& Puca, 2000), a "semi-projective" measure. Like in other picture-story-exercises (PSEs), participants are presented with pictures depicting social situations. In contrast to classical PSEs like the TAT (Murray, 1943) however, several items have to be rated, whether they fit to the displayed picture. According to the authors, the MMG thus allows the measurement of implicit motives, combining the motive-stimulating power of pictures with the economy of questionnaires. The MMG aims at measuring Affiliation, Achievement and Power, each with a hope component and a fear component.

As the MPZM is supposed to measure relatively stable behavioral tendencies, we decided to compare it also with a standard measure of personality, the German adaptation of the NEOFFI (Borkenau \& Ostendorf, 1991), assessing the five factor model (FFM) with its dimensions Neuroticism, Extraversion, Openness, Agreeableness and Conscientiousness. In addition to these questionnaires, participants answered several biographic questions which served as external criteria (for an overview see Table 4). As the security system is connected to the bonding system, it should predict a monogamous relationship preference and the 
desired number of children. The arousal system should predict, whether participants reported drug usage (at least once in their life). As the power motive is strongly connected to sexuality (see above), it should predict promiscuity (defined as sexual activity with multiple partners in the same period) and the desired frequency of sexual intercourse. Final grade points should be predicted by the achievement motive. The frequency of public appearances should be an indicator of the prestige motive.

Due to the strong functional interconnection of the arousal motive and the power motive (Bischof, 2001), in some criteria both systems could serve as predictors. Therefore in following criteria, we have to make the weaker prediction that either the arousal or the power motive is a predictor: traffic offenses (officially recorded), relationship preference (multiple partners in lifetime) and social activity (number of actively joined groups; cf. Bischof, 2001). The full sample $(n=190)$ completed the MPZM, the MMG, and biographical data. One subsample ( $\mathrm{n}=89)$ additionally completed the PRF-D, the second sub-sample $(\mathrm{n}=101)$ completed the NEO-FFI. Completion of the whole test package took about 50-70 minutes.

\section{Statistical Procedure}

Cronbach's $\alpha$ was computed for all scales. For assessing convergent and discriminant validity, intercorrelations of all used scales were computed and a multitrait-multimethod-analysis was conducted (Campbell \& Fiske, 1959). To explore the joint underlying factorial structure of the instruments, an exploratory principal axis factor analysis with Promax rotation $(\mathrm{kappa}=4)$ was computed on scale-level. For assessing external and incremental validity, bivariate as well as hierarchical multiple regressions were performed on the biographical statements.

\section{Results}

\section{Scale Properties}

Internal consistencies of the MPZM were comparable to those in the construction sample 
(Cronbach's $\alpha$ ranging from 0.73 to 0.80 , see Table 1 ). Again it showed an excellent factorial structure with all items loading highest on the correct factor and only two items having secondary loadings $>0.30$.

Internal consistencies for the MMG ranged from 0.58 to 0.77 (four of the six scales had an $\alpha$ $>0.70$ ), for the PRF-D from 0.51 to 0.85 ( 9 of the 14 scales had an $\alpha>0.70$ ) and for the NEO-FFI from 0.73 to 0.87 . The Kolmogorov-Smirnov-test for all scales of MPZM and NEO-FFI showed sufficient normal distribution ( $\mathrm{p}>0.14)$. For PRF-D, one scale (aggression) differed significantly from normal distribution, for MMG three scales (Fear of Failure, Hope of Power, Fear of Power).

\section{Convergent and Discriminant Validity}

Between both explicit measures of motivation (MPZM and PRF-D), theoretically matching scales were identified (for matching of scales see Table 2). Average convergent validity between theoretically matched scales was $r=0.55$. Average discriminant validity was $r=$ 0.24

\section{--- TABLE 2 ABOUT HERE ---}

The MMG showed basically blockwise correlation patterns with few differentiations between its scales. All MMG scales except Hope of Affiliation were positively correlated with MPZM Prestige and all three fear components were negatively related to MPZM Power. Given such a pattern of correlations, convergent validity cannot be assumed.

Concerning the NEO-FFI, two scales of the MPZM could be partly matched to the FFM: Arousal had a moderate positive relationship to Extraversion $(\mathrm{r}=.39)$ and Prestige had a moderate positive relationship to Neuroticism $(r=.45)$. The other three scales had substantial correlations ( $r>0.30)$ to two scales of the NEO-FFI (see Table 2).

\section{Factorial Structure on Scale Level}


As participants either completed the PRF-D (subsample 1; $n=89$ ) or the NEO-FFI (subsample $2 ; n=101$ ), factor analyses were computed within each subsample. The MMG scales were included in a first analysis of each subsample, but as all six scales either formed one distinct factor with few or no connections to the other factors or the hope and fear components each split up on one factor with no differentiation between scales, the inventory was excluded from further factor analyses.

As KMO MSA in subsample 2 only reached 0.56 , these data were unsuitable for factor analysis. Subsample 1 however showed an acceptable KMO MSA of 0.72 and the Bartlett-test resulted in $\mathrm{p}<0.000$. Principle axis factor analysis revealed five eigenvalues $>1: 4.21,2.94$, 2.73, 1.61 and 1.04; however, parallel analysis suggested four factors explaining $60 \%$ of variance. As the MPZM constructs are theoretically not supposed to be independent, the fourfactorial solution was then oblique rotated (Promax; kappa $=4$ ).

\section{--- TABLE 3 ABOUT HERE ---}

The pattern matrix (Table 3) revealed no strict simple structure. For Factors 1 to 3, the MPZM had one high-loading scale with no secondary loadings. MPZM Arousal contributes with a medium loading to Factor 4, however this scale had a secondary loading on Factor 1. MPZM Prestige did not load on a distinct factor but spread over Factor 1 and Factor 3. For PRF-D, 5 out of 14 scales had secondary loadings greater 0.30 .

\section{External and Incremental Validity}

Bivariate correlations were calculated between MPZM scales and biographical statements (see Table 4). Five out of seven expected correlations turned out to be significant with average $r=0.22$. Concerning the weaker prediction (either arousal or power motive), in one case both motives showed significant correlations, in two cases one of them with average $\mathrm{r}=0.18$. However, two expected correlations did not show up and three correlations were significant but not expected. 


\section{--- TABLE 4 ABOUT HERE ---}

To compare the predictive power of all used inventories, hierarchical multiple regressions of all scales of one inventory onto the biographical statements were calculated. To evaluate the incremental validity of the MPZM, it was (a) entered in step 1 and an alternative inventory in step 2 and (b) vice versa. Changes in $\mathrm{R}^{2}$ and the corresponding $\mathrm{p}$-value allow judging the incremental validity. As the inventories differ in their number of scales (PRF-D: 14 scales, MMG: 6 scales, MPZM: 5 scales, NEO-FFI: 5 scales), adjusted values for $\mathrm{R}^{2}$ and $\Delta \mathrm{R}^{2}$ are reported.

\section{--- TABLE 5 ABOUT HERE ---}

Table 5 reports those findings. Results differ in some cases from the bivariate calculation (Table 4) due to the higher number of predictors and the adjusted calculation of $\mathrm{R}^{2}$.

Concerning the MPZM also a sample dependency can be observed - predictions in subsample 1 and subsample 2 differ in some cases. The most extreme example is the criterion of drug usage, which was predicted in subsample 1 with an adjusted multiple $\mathrm{R}^{2}$ of 0.16 , while the model did not reach significance in subsample 2.

MPZM made the most frequent significant predictions, but overall the PRF-D explained most of the variance. However, only in one criterion (desired frequency of sexual intercourse) the PRF-D showed significant incremental validity over the MPZM. MPZM showed incremental validity over NEO-FFI and MMG in more cases and in a higher range than vice versa. Average criterion validities (computed from $\mathrm{R}^{2}$ in step 1, regardless of significance) and average incremental validities (computed from $\Delta \mathrm{R}^{2}$ in step 2, regardless of significance) are reported in Table 6. Controlling for age and gender (results not reported here), yielded only minor changes with the overall pattern unchanged.

--- TABLE 6 ABOUT HERE ---

\section{Discussion}


In this article, we presented a new questionnaire for measuring interindividual differences in five motivational systems, using the Zurich Model of Social Motivation (Bischof, 2001) as a framework of evolutionary, well-grounded motives.

Psychometrically, the MPZM showed sufficient internal consistencies $(\alpha>0.73)$, as well as an excellent factorial structure. With all items loading on the correct factor, the MPZM showed a higher factorial validity than a re-analysis of the NEO-FFI items in a German sample, where 12 out of 60 items $(20 \%)$ had primary loadings on an unexpected factor ( $\mathrm{n}=1908$; Körner, Geyer, \& Brahler, 2002). The components of the autonomy system (power, prestige and achievement) showed moderate positive correlations, as expected. As the functional connection of security, arousal and autonomy system does not imply a correlation of absolute values of set points at group level, the obtained correlations between these scales neither support nor contradict the ZM.

The MPZM also showed convergent $(\mathrm{r}=0.55)$ and a moderate discriminant validity in comparison with the PRF-D. But as the scales differ in their theoretical background, the convergent validity was not assumed to be very high. A factor analysis of MPZM and PRF-D scales resulted in a four-factorial solution. The MPZM had strong markers on all factors and therefore seems to cover a broad range of human motivation.

Relations to the NEO-FFI scales were complex, suggesting that the MPZM does not simply mirror the constructs of the FFM. In the bivariate analysis, two MPZM scales (Arousal and Prestige) showed meaningful correlations to corresponding NEO-FFI scales (Extraversion and Neuroticism), but the other three MPZM scales had multiple moderate significant correlations to NEO-FFI scales.

Bivariate correlations of MPZM scales and biographical statements in most cases followed the expected pattern. Although the MPZM only has half the number of items of the NEO-FFI and about one eighth of the items of the PRF-D, it made most frequently significant 
predictions in biographical statements. The PRF-D showed the highest multiple correlations, what is not surprising due to its much higher resolution and temporal diagnostic effort. Except for that, the MPZM surpassed NEO-FFI and MMG both in criterion and incremental validity. However, low overall predictive validity of all inventories can have different causes: First, a given motive can energize very different behaviors (Murray, 1938). For example, the achievement motive can manifest itself in occupational efforts (which would be the stereotypical "high-achiever"), but it could just as well be found in efforts to be the best house husband in the neighborhood. Therefore these correlations, which examine a relation between motive strength and behavior on group level, might not be the best test for the external validity of a motive measure, because they cannot reflect idiosyncratic ways in expressing a motive (see also Asendorpf, 2000). A more sophisticated way could be the examination of the interaction between motives and personality traits (or the "Why" and the "How" of behavior; see Winter et al., 1998). Furthermore, predictions of life outcomes like recorded traffic offenses or drug usage are generally hard to make because these are multiply determined. In the following section, each of the five scales is discussed in relation to the findings in the present study.

Power: In the scale level factor analysis of MPZM and PRF-D, this scale had the highest loading on Factor 1, along with PRF dominance. In the prediction of biographical events, the scale had a positive relation to promiscuity, which is in line with the theoretical assumption. The expected correlation to the desired sex frequency was not found, what possibly is due to the compromising nature of the question.

Security: In the scale level factor analysis, this scale showed a strong relationship to PRF succorance and - not so expected - to PRF social recognition. It had a single loading on Factor 3. PRF affiliation had also a moderate loading on this factor, but also loaded high on Factor 4 (an "arousal" factor, see below). So, in terms of the ZM, the affiliation motive (at 
least in the PRF-D version) could be interpreted as a mixture of two more basal motivations: a high need for security combined with a high need for arousal. Security showed a positive relation to the desired number of children and a positive relation to a monogamous relationship preference, which is perfectly in line with the theoretical assumptions. Arousal: This scale loaded on one factor along with PRF play, harmavoidance and order. But it also had a moderate secondary loading on Factor 1, the "power" factor, which could reflect the theoretical positive relation between the arousal system and the autonomy system. As expected, Arousal predicted drug usage. In two criteria (relationship preference and desired frequency of sexual intercourse) it made significant predictions, although Power was expected to be the stronger predictor. But as sexuality can have multiple functions in humans, it also can be determined by multiple motivational systems.

Achievement: This classical motivational construct loaded highly on one factor, together with PRF achievement, endurance and understanding, which was the expected pattern. As expected, Achievement predicted the final grade point average. The positive relation to traffic offenses and to the desired sex frequency was unexpected - but as the achievement motivation does not predict the domain of achievement (see above), it is imaginable that sexual intercourse or driving style can be associated with achievement motivation.

Prestige: This scale is the only one that does not form an independent factor, but rather seems to be a combination of power and security. In the scale level factor analysis, it had a complementary loading pattern to PRF succorance: both load high on the "security factor", so both reflect the need for intimate relationships. But people high on succorance have a low loading on the power factor, while people with a high need for prestige can enforce their need for security with some dominance. The criterion validity of this scale can be questioned as it did not show any significant correlation to the criteria in study. But due to its good factorial validity and internal consistency, it is preliminary retained in the inventory. Future studies 
have to show whether the scale proves to be useful.

\section{Limitations and Future Directions}

A limitation of the present study is the relative small number of participants and the unrepresentative sample in the validation study. As the motivational set points are supposed to be relatively stable dispositions, a reasonable next step lies in the investigation of the instrument's retest stability. Future research might also explore various types of validity: differentiation of groups, prediction of behavior in labor situations or diary studies. Furthermore, one big advantage of the ZM is the dynamic modeling of motivational processes. In terms of systems theory, we carried out a stationary system analysis (Bischof, 1993), where stable parameters from an inactive system are assessed. The next step - dynamic system analysis - also considers the time axis, and in this analysis, the full advantage of system modeling comes to effect.

To summarize, the MPZM is a reliable instrument, solidly based on a theory of motivation the Zurich Model of Social Motivation. Comprising only 30 items, it is short and easy to administer, showed convergent validity to other explicit measures of motivation and allowed a significant prediction of select biographical data in the actual sample (except Prestige). In its predictive power, it outperformed the NEO-FFI and the MMG. Although the PRF-D showed somewhat better results in most cases, one has to take its length into consideration. In short, with the half of the items of the NEO-FFI and one eighth of the items of the PRF-D, the MPZM is a very economic measure for a broad screening of human motives.

\section{References}

Asendorpf, J. B. (2004). Psychologie der Persönlichkeit. 3. Auflage. Berlin: Springer.

Asendorpf, J. B. (2000). Idiographische und nomothetische Ansätze in der Psychologie. 
Bischof, N. (1975). A systems approach toward the functional connections of attachment and fear. Child Development, 46(4), 801-817.

Bischof, N. (1993). Untersuchungen zur Systemanalyse der sozialen Motivation I: Die Regulation der sozialen Distanz--Von der Feldtheorie zur Systemtheorie. Zeitschrift für Psychologie, 201(1), 5-43.

Bischof, N. (2001). Das Rätsel Ödipus. Die biologischen Wurzeln des Urkonflikts von Intimität und Autonomie. München: Piper.

Block, J. (2002). Personality as an affect-processing system: Toward an integrative theory. Mahwah, NJ, US: Lawrence Erlbaum Associates Publishers.

Borkenau, P. \& Ostendorf, F. (1991). Ein Fragebogen zur Erfassung fünf robuster Persönlichkeitsfaktoren. Diagnostica, 37(1), 29-41.

Bowlby, J. (1980). Attachment and loss. New York, NY, US: Basic Books.

Campbell, D. T. \& Fiske, D. W. (1959). Convergent and discriminant validation by the multitrait-multimethod matrix. Psychological Bulletin, 56(2), 81-105.

Diamond, L. M. (2004). Emerging perspectives on distinctions between romantic love and sexual desire. Current directions in psychological science, 13, 116-119.

Gubler, H. \& Bischof, N. (1991). A systems theory perspective. In M. E. Lamb \& H. Keller (Eds.), Infant development: Perspectives from German-speaking countries. (pp. 35-66). Hillsdale, NJ, England: Lawrence Erlbaum Associates, Inc.

Gubler, H. \& Bischof, N. (1993). Untersuchungen zur Systemanalyse der sozialen Motivation II: Computerspiele als Werkzeug der motivationspsychologischen Grundlagenforschung. Zeitschrift für Psychologie, 201(3), 287-315.

Hazan, C. \& Shaver, P. R. (1994). Attachment as an organizational framework for research on close relationships. Psychological Inquiry, 5(1), 1-22. 
Horn, J. L. (1965). A rationale and test for the number of factors in factor-analysis. Psychometrika, 30(2), 179-185.

Jackson, D. N. (1967). Manual for the Personality Research Form. Goshen: Research Psychologist Press.

Körner, A., Geyer, M., \& Brahler, E. (2002). Das NEO-Fünf-Faktoren Inventar (NEO-FFI): Validierung anhand einer deutschen Bevölkerungsstichprobe. Diagnostica, 48(1), 19-27.

Lamb, M. E., Bornstein, M. H., \& Teti, D. M. (2002). Development in infancy: An introduction (4th ed.). Mahwah, NJ, US: Lawrence Erlbaum Associates Publishers.

Lamb, M. E. \& Keller, H. (1991). Infant development: Perspectives from German-speaking countries. Hillsdale, NJ, England: Lawrence Erlbaum Associates, Inc.

McClelland, D. C., Koestner, R., \& Weinberger, J. (1989). How do self-attributed and implicit motives differ? Psychological Review, 96, 690-702.

Murray, H. A. (1938). Explorations in personality. New York: Oxford University Press.

Murray, H. A. (1943). Thematic Apperception Test Manual. Cambridge, MA: Harvard University Press.

Pollak, S. D. (2005). Early adversity and mechanisms of plasticity: Integrating affective neuroscience with developmental approaches to psychopathology. Development and Psychopathology, 17(3), 735-752.

Schmalt, H.-D., Sokolowski, K., \& Langens, T. (2000). Das Multi-Motiv-Gitter für Anschluß, Leistung und Macht (MMG): Manual. Frankfurt am Main: Swets \& Zeitlinger BV.

Schultheiss, O. C. (2001). An information processing account of implicit motive arousal. In M. L. Maehr \& P. Pintrich (Eds.), Advances in motivation and achievement (Vol. 12: New directions in measures and methods). (pp. 1-41). Greenwich, CT: JAI Press. 
Sokolowski, K., Schmalt, H.-D., Langens, T. A., \& Puca, R. M. (2000). Assessing achievement, affiliation, and power motives all at once: The Multi-Motive Grid (MMG). Journal of Personality Assessment, 74, 126-145.

Stumpf, H., Angleitner, A., Wieck, T., Jackson, D. N., \& Beloch-Till, H. (1985). Deutsche Personality Research Form (PRF): Handanweisung. Göttingen: Hogrefe.

Winter, D. G., John, O. P., Stewart, A. J., Klohnen, E. C., \& Duncan, L. E. (1998). Traits and motives: Toward an integration of two traditions in personality research. Psychological Review, 105(2), 230-250.

\section{Tables}

Table 1: Internal consistencies of the five MPZM-scales

\begin{tabular}{|l|c|c|c|}
\hline Scale & $\alpha$ (optimization sample, $\mathrm{n}=622)$ & $\alpha$ (validation sample, $\mathrm{n}=621)$ & $\alpha$ (sample study II, $\mathrm{n}=190)$ \\
\hline Security & .73 & .75 & .79 \\
\hline Arousal & .82 & .80 & .80 \\
\hline Power & .78 & .75 & .75 \\
\hline Prestige & .75 & .73 & .77 \\
\hline Achievement & .76 & .71 & .73 \\
\hline
\end{tabular}

Table 2: Bivariate intercorrelations of scales

\begin{tabular}{|l|l|l|l|l|l|}
\hline & $\begin{array}{l}\text { MPZM } \\
\text { Security (Sec) }\end{array}$ & $\begin{array}{l}\text { MPZM } \\
\text { Arousal } \\
\text { (Arou) }\end{array}$ & $\begin{array}{l}\text { MPZM Power } \\
\text { (Pow) }\end{array}$ & $\begin{array}{l}\text { MPZM } \\
\text { Prestige (Pre) }\end{array}$ & $\begin{array}{l}\text { Achievement } \\
\text { (Ach) }\end{array}$ \\
\hline MPZM Security & 1 & -.03 & .04 & $.43^{* *}$ & .12 \\
\hline MPZM Arousal & -.03 & 1 & $.35^{* *}$ & .08 & $.19^{* *}$ \\
\hline MPZM Power & .04 & $.35^{* *}$ & 1 & $.24^{* *}$ & $.40^{* *}$ \\
\hline
\end{tabular}




\begin{tabular}{|c|c|c|c|c|c|}
\hline MPZM Prestige & $.43^{* *}$ & .08 & $.24 * *$ & 1 & .08 \\
\hline NEO neuroticism & $.37 * *$ & -.16 & -.09 & $.45 * *$ & -.13 \\
\hline NEO extraversion & $.40 * *$ & $.39 * *$ & $.32 * *$ & .19 & $.32 * *$ \\
\hline NEO openness & -.10 & .15 & -.08 & -.14 & .12 \\
\hline NEO agreeableness & .14 & .06 & $-.37 * *$ & -.16 & -.01 \\
\hline NEO conscientiousness & .16 & -.04 & .11 & -.06 & $.59 * *$ \\
\hline PRF achievement & -.02 & 20 & $.35 * *$ & -.16 & $.66^{* *}$ \\
\hline PRF affiliation & $.37 * *$ & $.27 *$ & .15 & .17 & .20 \\
\hline PRF aggression & .05 & $.24 *$ & $.23 *$ & .10 & .15 \\
\hline PRF dominance & .05 & $.48 * *$ & $.76 * *$ & .06 & $.44 * *$ \\
\hline PRF endurance & -.12 & .06 & .12 & $-.28 * *$ & $.55 * *$ \\
\hline PRF exhibition & .11 & $.45 * *$ & $.51 * *$ & .19 & .10 \\
\hline PRF harmavoidance & .18 & $-.71 * *$ & $-.38 * *$ & .14 & -.18 \\
\hline PRF impulsivity & .13 & .11 & .12 & .08 & $-.26^{*}$ \\
\hline PRF nurturance & $.30 * *$ & .05 & -.09 & -.04 & .16 \\
\hline PRF order & .02 & $-.22 *$ & .02 & .08 & .15 \\
\hline PRF play & .07 & $.40 * *$ & .12 & .12 & -.09 \\
\hline PRF social recognition & $.38 * *$ & -.15 & .04 & $.60 * *$ & .20 \\
\hline PRF succoranc & $.48 * *$ & $-.26^{*}$ & $-.26^{*}$ & $.39 * *$ & -.08 \\
\hline PRF understanding & -.04 & .15 & .12 & .03 & $.35 * *$ \\
\hline MMG hope of affiliation & .11 & $.21 * *$ & -.01 & .08 & .08 \\
\hline MMG fear of rejection & .14 & -.04 & $-.17 *$ & $.18^{*}$ & -.06 \\
\hline MMG hope of success & .09 & $.17 *$ & $.21 * *$ & $.16^{*}$ & .14 \\
\hline MMG fear of failure & $.20 * *$ & $-.15^{*}$ & $-.18 *$ & $.25 * *$ & -.09 \\
\hline MMG hope of power & .09 & $.29 * *$ & $.15^{*}$ & $.28 * *$ & .12 \\
\hline MMG fear of power & .14 & -.13 & $-.21 * *$ & $.19 * *$ & -.05 \\
\hline
\end{tabular}

Note: Theoretically assumed convergent coefficients between MPZM and PRF-D are underlined; * $\mathrm{p}<0.5, * * \mathrm{p}<0.01$. 
Table 3: Pattern matrix of Promax-rotated factor loadings for MPZM and PRF-D scales $(\mathrm{n}=89)$. Loadings $>0.30$ are printed in bold-face.

\begin{tabular}{|c|c|c|c|c|}
\hline & \multicolumn{4}{|c|}{ Factors } \\
\hline & 1 & 2 & 3 & 4 \\
\hline PRF dominance & .82 & .17 & .02 & .07 \\
\hline MPZM Power & .79 & .09 & -.05 & -.02 \\
\hline PRF exhibition & .59 & -.11 & .18 & .38 \\
\hline PRF aggression & .32 & -.09 & .01 & .10 \\
\hline PRF endurance & -.11 & .75 & -.17 & -.13 \\
\hline PRF achievement & .20 & .73 & -.06 & -.16 \\
\hline MPZM Achievement & .30 & .69 & .14 & -.25 \\
\hline PRF understanding & -.04 & .43 & .10 & .07 \\
\hline PRF nurturance & -.34 & .42 & .38 & .24 \\
\hline PRF social recognition & .15 & .05 & .74 & -.25 \\
\hline PRF succorance & -.31 & -.02 & .70 & .03 \\
\hline MPZM Security & -.02 & .00 & .63 & .02 \\
\hline MPZM Prestige & .32 & -.25 & .61 & -.15 \\
\hline PRF affiliation & .02 & .26 & .49 & .35 \\
\hline PRF play & .09 & -.13 & .10 & .67 \\
\hline PRF harmavoidance & -.17 & -.28 & .24 &.- .59 \\
\hline PRF order & .06 & .24 & .17 & -.52 \\
\hline MPZM Arousal & .35 & .15 & -.16 & .51 \\
\hline PRF impulsivity & .21 & -.42 & .06 & .48 \\
\hline
\end{tabular}

Table 4: Bivariate correlations of MPZM scales with criteria $(n=190)$. Expected correlations are underlined; if either the arousal or the power motive are expected, both are dashed underlined. Abbreviations of scales: see Table 2. 


\begin{tabular}{|l|c|c|c|c|c|}
\hline Criterion & Sec & Arou & Pow & Pre & Ach \\
\hline Drug Usage & .02 & $.28^{* *}$ & .08 & .03 & -.02 \\
\hline Traffic Offenses & .12 & .11 & .21 * $^{* *}$ & -.02 & $.21^{* *}$ \\
\hline social activity (number of actively joined groups) & .03 & $.16^{*}$ & $.18^{*}$ & -.02 & .09 \\
\hline social activity (frequency of public appearances) & -.05 & .05 & .02 & -.05 & -.08 \\
\hline final grade point average & .00 & .02 & -.14 & -.05 & $-.27^{* *}$ \\
\hline relationship preferences (monogamous vs. multiple partners in life) &.$- .17^{*}$ & $.18^{*}$ & .04 & .10 & -.03 \\
\hline desired number of children & $.20^{* *}$ & .10 & .00 & .12 & .04 \\
\hline promiscuity ("Have you ever had sex with multiple partners in the & -.10 & .13 & $.17^{*}$ & -.03 & .07 \\
same period?") & & & & & \\
\hline desired frequency of sexual intercourse & -.02 & $.23^{* *}$ & .13 & .03 & $.21^{* *}$ \\
\hline
\end{tabular}

Table 5: Pairwise head-to-head comparison of inventories in the prediction of criterion variables by hierarchical multiple regressions.

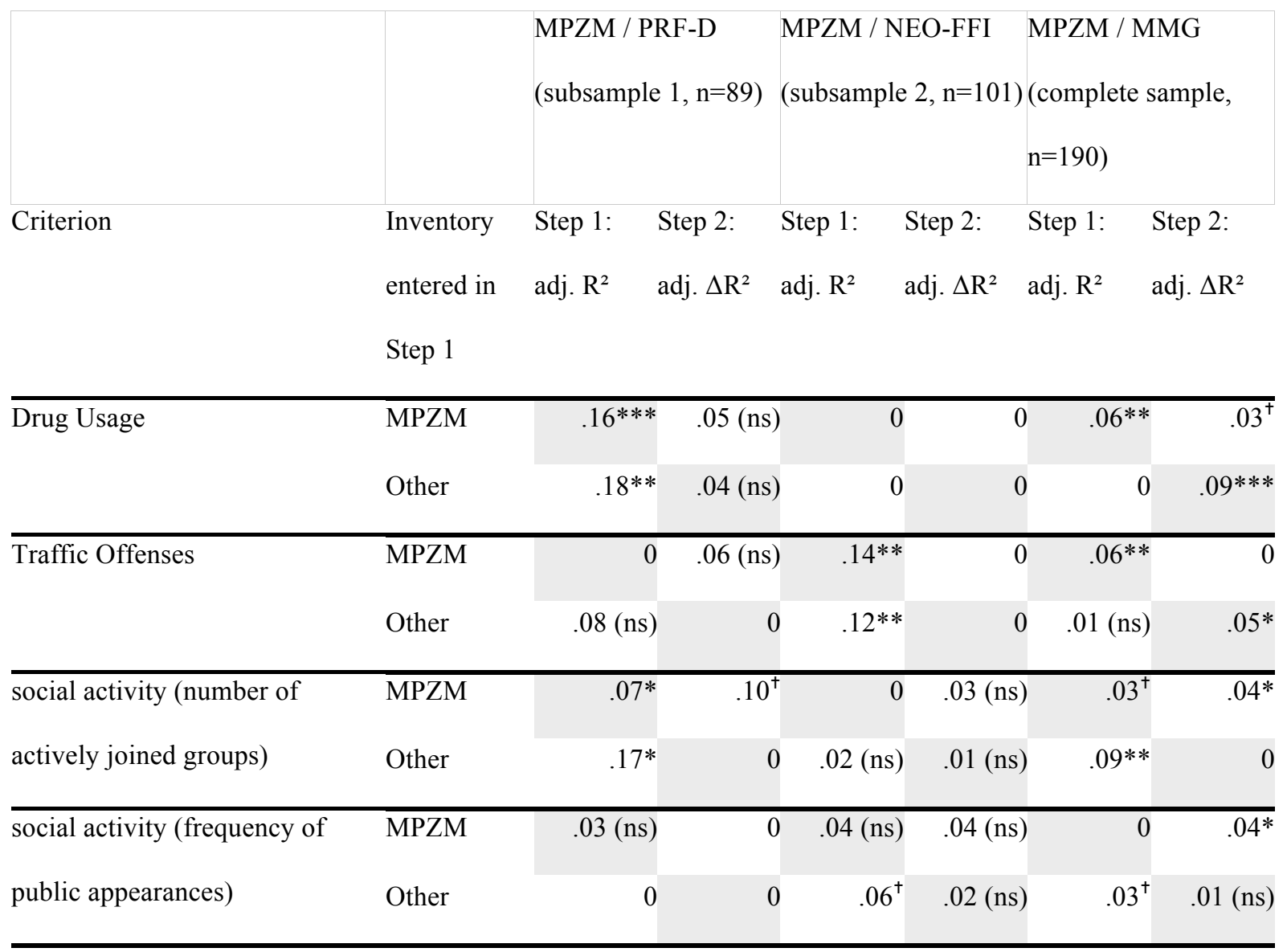




\begin{tabular}{|c|c|c|c|c|c|c|c|}
\hline \multirow[t]{2}{*}{ final grade point average } & MPZM & .04 (ns) & 0 & $.10^{*}$ & .02 (ns) & $.06^{*}$ & $.01(\mathrm{~ns})$ \\
\hline & Other & .02 (ns) & 0 & .03 (ns) & $.09 *$ & 0 & $.07 * *$ \\
\hline \multirow[t]{2}{*}{ relationship preferences } & MPZM & $.07^{\dagger}$ & .05 (ns) & $.05^{\dagger}$ & .03 (ns) & $.07 * *$ & $.05^{*}$ \\
\hline & Other & $.06(\mathrm{~ns})$ & $.06^{\dagger}$ & $.02(\mathrm{~ns})$ & $.06^{\dagger}$ & $.05 *$ & $.07 * *$ \\
\hline \multirow[t]{2}{*}{ desired number of children } & MPZM & .02 (ns) & 0 & 0 & 0 & $.03^{\dagger}$ & $\overline{0}$ \\
\hline & Other & 0 & 0 & 0 & 0 & $.02(\mathrm{~ns})$ & $.01(\mathrm{~ns})$ \\
\hline \multirow[t]{2}{*}{ promiscuity } & MPZM & $.04(\mathrm{~ns})$ & .07 (ns) & 0 & $\overline{0}$ & .02 (ns) & $\overline{0}$ \\
\hline & Other & $.12 *$ & 0 & $.01(\mathrm{~ns})$ & 0 & .02 (ns) & 0 \\
\hline desired frequency of sexual & MPZM & $.02(\mathrm{~ns})$ & $.20^{*}$ & $.13^{* *}$ & 0 & $.06^{*}$ & 0 \\
\hline intercourse & Other & $.16^{*}$ & $.06^{\dagger}$ & $.03(\mathrm{~ns})$ & $.09 *$ & $.01(\mathrm{~ns})$ & $.04^{\dagger}$ \\
\hline
\end{tabular}

Note: First order multiple regressions of MPZM and incremental validities of MPZM over alternative inventories are shaded.

Table 6: Average criterion and incremental validities. Coefficients are calculated from adjusted $\mathrm{R}^{2}$, regardless of significance. Numbers of significant models refer to the overall number of nine criteria (e.g., 5 out of 9 criteria were significantly predicted by MPZM)

\begin{tabular}{|c|c|c|c|}
\hline Inventory & $\begin{array}{l}\text { criterion validity } \\
\text { (average } r \text { / number of } \\
\text { significant models in } \\
\text { step 1) }\end{array}$ & $\begin{array}{l}\text { incremental validity of } \\
\text { MPZM over other inventory } \\
\text { (average } r / \text { number of } \\
\text { significant } \Delta \mathrm{R}^{2} \text { ) }\end{array}$ & $\begin{array}{l}\text { incremental validity of other } \\
\text { inventory over MPZM } \\
\text { (average } \mathrm{r} / \text { number of } \\
\left.\text { significant } \Delta \mathrm{R}^{2}\right)\end{array}$ \\
\hline MPZM (complete sample) & $.19(5)$ & - & - \\
\hline PRF-D & $.23(4)$ & $.07(0)$ & $.18(1)$ \\
\hline NEO-FFI & $.15(1)$ & $.12(2)$ & $.08(0)$ \\
\hline MMG & $.13(2)$ & $.16(4)$ & $.10(3)$ \\
\hline
\end{tabular}

